\title{
Representación y continuidad iconográfica de templos del Horizonte Temprano al Horizonte Tardío y Período Virreynal (700 a. C.-1615 d. C.)
}

Representation and iconographic continuity of temples from the Early Horizon to the Late Horizon and the Viceroyalty Period (700 B.C - A.D 1615)

\author{
Jorge A. Calero Flores \\ https://orcid.org/000o-0003-3469-6838 \\ Universidad Nacional de San Antonio Abad del Cusco \\ jorge.calero@unsaac.edu.pe
}

\section{RESUMEN}

Esta investigación muestra la continuidad iconográfica de arquitectura pública o templos, desde el año 700 a. C. al año 1615 d. C., representación que se inicia en el Horizonte Temprano con la escena presente en la pluma Echenique (700 a 600 años a. C.), en la que se aprecian dos celebrantes que flanquean un templo de forma circular con dos ofrendatorios. Posteriormente, esta primera iconografía de arquitectura es representada en forma de la letra " $\mathrm{H}$ " mayúscula, preferentemente en estilos tempranos y, luego, es invertida en la iconografía tardía, tomando la forma de la letra "I" mayúscula, la que continúa hasta la época virreynal en 1615, situación evidenciada por Guamán Poma de Ayala (1615), quien registra personajes collas de la época inca y la época virreynal, los mismos que llevan como gargantilla el ícono de la " $\mathrm{H}$ " invertida o la "I" representativa de la arquitectura religiosa.

Palabras clave: Iconografía; Horizonte Temprano; Horizonte Tardío; Período Virreynal; pluma Echenique; continuidad iconográfica; representación iconográfica de arquitectura. 


\section{ABSTRACT}

This research shows the iconographic continuity of public architecture or temples, since $700 \mathrm{BC}$ to $1615 \mathrm{~A}$ C, representation that begins in the Early Horizon with the scene present in the pluma Echenique (700 to 600 years $\mathrm{BC}$ ), where two celebrants are seen flanking a circular temple with two ofrendatories. Subsequently, this first architectural iconography is represented in the form of the uppercase letter " $\mathrm{H}$ ", preferably in early styles, and then it is inverted in late iconography, taking the form of the uppercase letter "I", which continues until colonial era in 1615, a situation evidenced by Guamán Poma de Ayala (1615), who records characters from the Inca period and the colonial period, the same ones who wear the icon of the inverted " $\mathrm{H}$ " or the "I" representative of the religious architecture.

Keywords: Iconography; Early Horizon; Late Horizon; Viceroyalty Period; Pluma Echenique; iconographic continuity; iconographic representation of architecture.

RECIBIDO: 14/09/2020 - ACEPTADO: 16/09/2020 - PubLICADO: 25/06/2021

\section{EL PERÚ Y EL CUZCO}

El presente trabajo de investigación se desarrolla en el territorio situado en la parte central occidental de América del Sur, en una extensión que comprende el departamento de La Paz (Tiahuanaco) en Bolivia; la región de Antofagasta (San Pedro de Atacama) en Chile y en Perú, las regiones de Puno, Moquegua, Arequipa, Ayacucho, Apurímac y Cuzco. Este último se halla ubicado en la región andina al centro sur del país y posee amplia diversidad de paisajes y recursos naturales propios de sus pisos ecológicos, cuyos límites extremos van desde los 700 hasta los $6300 \mathrm{~m} \mathrm{s.} \mathrm{n}$. $\mathrm{m}$. En Cuzco se enmarcan altas montañas, valles interandinos, la amazonía alta y el llano amazónico; constituyéndose como el epicentro de la iconografía abordada en el presente análisis estilístico (figura 01).

\section{ANTECEDENTES}

En Cuzco, por el año 1853, el expresidente peruano José Rufino Echenique Benavente, en su condición de dignatario, recibió como obsequio una colección de objetos de oro que, con el tiempo, fue conocida como "La colección Echenique" (figura 02a y 02c).

El 15 de octubre de 1853, una dama de la aristocracia limeña lució la pluma Echenique como prendedor en el suntuoso baile de La Victoria que el, entonces, presidente peruano Rufino Echenique ofreció al Congreso de La República y a la aristocracia limeña (Tello, 1938). En dicha fecha, el joven Markham, capitán de la armada británica, tomó conocimiento de la colección Echenique y hacia mediados del siglo XIX incluyó una breve referencia de esta colección en su libro Cuzco: 


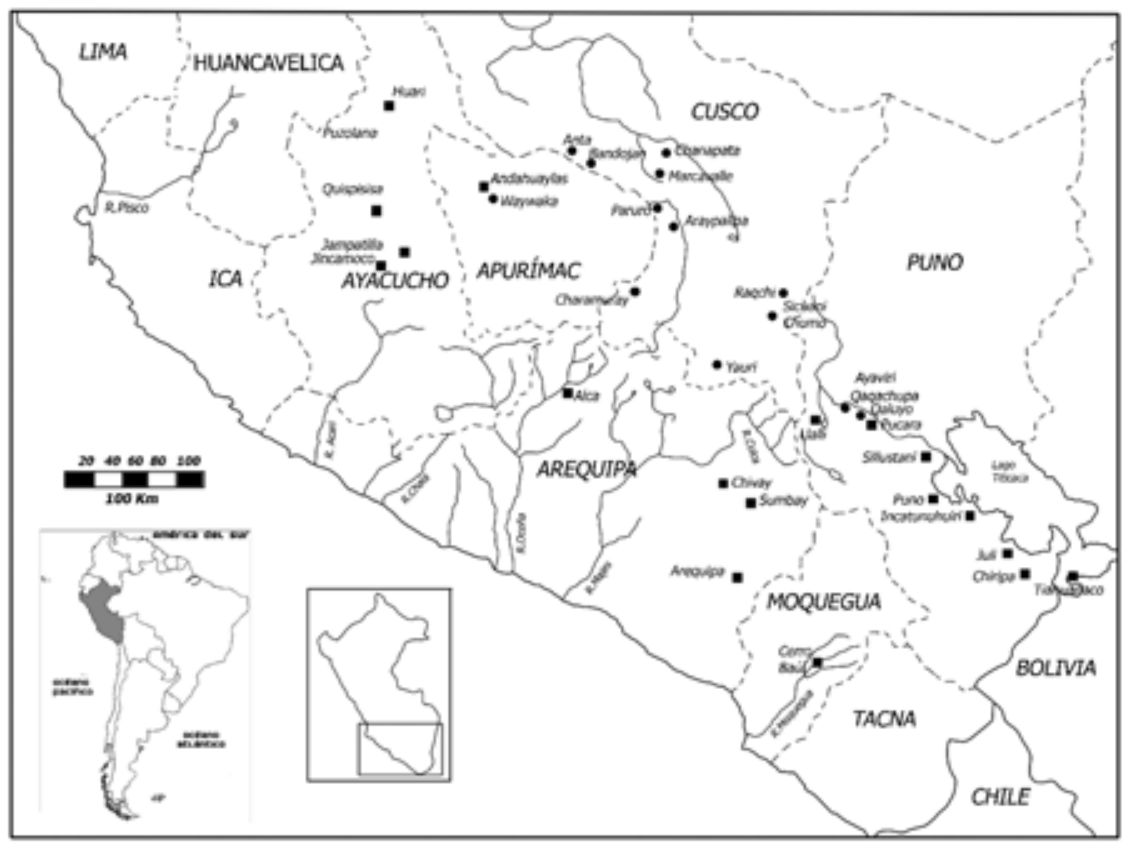

Figura 01. Mapa del sur de Perú.

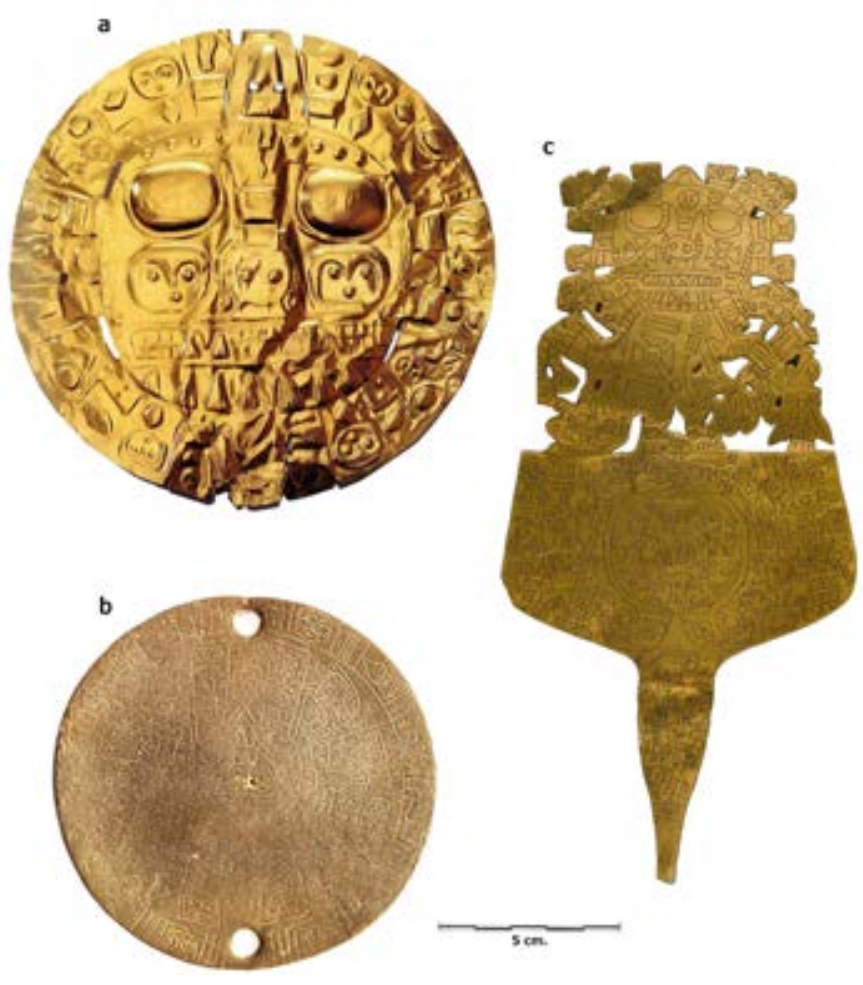

Figura 02. a) Disco Echenique faccionado en oro laminado, repujado y calado. Actualmente conservado en el $\mathrm{Mu}$ seo del Indio Americano, Heye Foundation, EE.UU.

b) Pluma Echenique lograda en oro laminado, cincelado $y$ calado. Actualmente conservado en el Museo Metropolitano de Arte de Nueva York, EE.UU.

c) Disco Oberti, laminado y cincelado en bronce. Actualmente conservado en el Museo Nacional de Arqueología, Antropología e Historia del Perú. Foto: A. María Jhong. 
A journey to the ancient capital of Peru; with an account of the history, language, literature, and antiquities of the Incas. And Lima: A visit to the capital and provinces of modern Peru; with a sketch of the viceregal government, history of the republic, and a review of the literature and society of Peru (Markham, 1856).

Más adelante, el mismo autor publicó Los Incas del Perú, donde hace un recuento del registro de estas piezas que había examinado el 25 de octubre de 1853, durante su estadía en la ciudad de Lima (Markham, 1920, p. 104).

Hacia 1923, en su artículo intitulado "Wiracocha", Tello asocia a los personajes representados en el disco y la pluma Echenique a cabezas de felino con cuatro apéndices, relacionándolos al dios Wiracocha (Tello, 1923: 132-138). Sin embargo, no es sino hasta 1938, que este investigador hace un minucioso análisis de la iconografía de la pluma, describiendo al personaje principal como un felino humanizado (Tello, 1938).

Otro importante estudio para el entendimiento de la colección Echenique, lo realiza John H. Rowe en 1976, quien adiciona a este corpus el disco Oberti (figura 02b), descubierto en 1975, llegando a la conclusión de que estas tres piezas constituyen el antecedente de estilos iconográficos posteriores como Pucara, Tiahuanaco, Wari y otros; y situándolas en la Fase 6 de la columna maestra de Ocucaje (Paracas), equivalente a 900 años a. C. (Rowe, 1976, p. 01-15).

En el año 1997, concluí un estudio previo de las tres piezas en referencia, publicado en la revista del Instituto de Investigaciones Antropológicas Qollana, en el cual planteo que esta colección, más bien se ubicaría en la Fase 8 de la columna maestra de Ocucaje (Paracas), equivalente a los años 700 a 600 a. C., esto porque se encuentran íconos relacionados al estilo cuzqueño Chanapata correspondiente a los años 600 a 200 a. C., así como similitudes estilísticas con otros íconos de la misma fase (Calero, 1997, p. 30-33). Para una mejor referencia, ver el cuadro cronológico signado como (ver figura 03).

Para el año 2000, publiqué un pequeño artículo en la revista Vía Láctea, en el que resalto la condición de piezas únicas a la colección Echenique y disco Oberti, proponiendo su filiación cultural al estilo cuzqueño Chanapata (Calero, 2000, p. 16).

Por otro lado, Margaret Young (2004, p. 94) publica, más adelante, un artículo donde realiza una descripción de la pluma Echenique y brinda algunas importantes aproximaciones referentes a su contenido iconográfico, entre ellas, la presencia de arquitectura.

John H. Rowe (1976, p. 04) había advertido no poder profundizar sus estudios por la ausencia de dibujos fiables de dicha colección; es así que a inicios del año 2017 revisé mis notas, gráficos y fotos de trabajo acerca de la colección Echenique y logré realizar un dibujo preciso de la pluma (figura 04), en base al cual identifiqué plantas maestras o enteógenas en la iconografía de dichas piezas (Calero, 2018), sumándose a ello también lo planteado por Young (2004: 94), Fernández P. (2017: 02) y Calero 


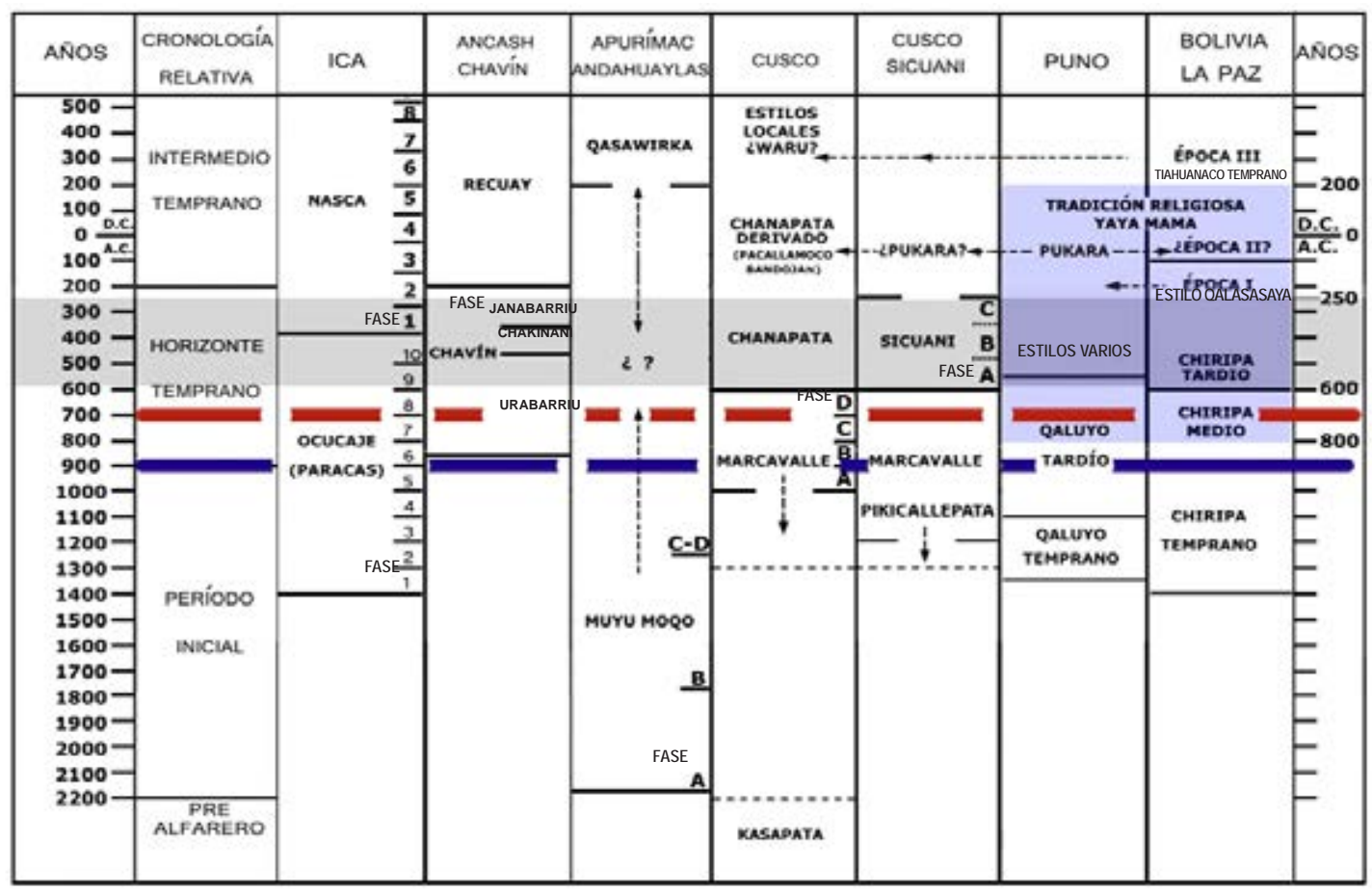

Jorge A. Calero F. y Mildred Fernández Palomino, 2014

Figura 03. Cuadro cronológico tomado de Calero y Fernández (2019: 167). La línea azul marca la propuesta cronológica planteada por Rowe, para el disco Oberti, la pluma y disco Echenique. La línea roja señala nuestra propuesta cronológica para las mismas piezas antes indicadas.

(2018, p. 65), en cuanto a la representación de arquitectura religiosa; abriéndose así, la posibilidad que esta iconografía continúe hasta el Período Intermedio Tardío y Horizonte Tardío o Inca (Calero, 2017, p. 4-5; 2018, p. 99-100).

\section{LA CRONOLOGÍA DE LA PLUMA ECHENIQUE}

Rowe se refiere a la cronología del disco Oberti, la pluma y disco Echenique, indicando:

"...tenemos entonces, tres piezas metálicas de la región del Cuzco con una fecha relativa de más o menos la Época 6 del Horizonte Temprano, fecha calculada en base a parecidos con la cerámica de Paracas que abarcan muchos detalles. En términos de la escala radiocarbónica, se trata probablemente de la primera mitad del primer milenio antes de nuestra era" (Rowe, 1976, p. 07-08).

Teniendo en cuenta la cronología publicada por Rowe (1960, p. 03-05), la Fase 6 de Ocucaje o Paracas, que enmarca el espacio de tiempo comprendido entre 900 a 800 años a. C., y la primera mitad del primer milenio antes de Cristo, correspondiendo a las fases 9 y 10 de Ocucaje o Paracas. Como consecuencia, se infiere que 

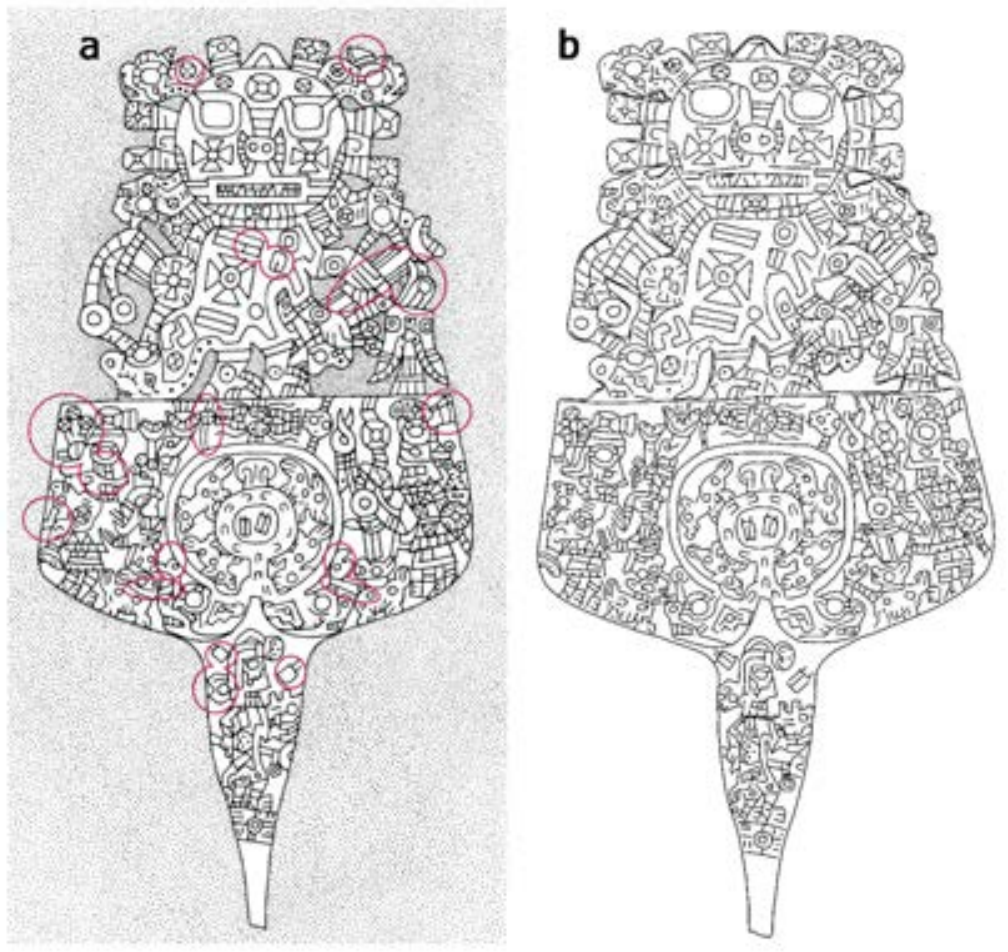

Figura 04. Pluma Echenique: a) Dibujo realizado por Ponce Sánchez en 1938. b) Dibujo realizado por el autor en base a fotografías digitales. Los círculos resaltan las alteraciones realizadas en la iconografía por Ponce Sánchez.

Rowe habría planteado dos fechas: la primera, de 900 a 800 años a. C., y la segunda, de 600 a 500 a. C.

Según, las comparaciones iconográficas de la columna de Ica (Menzel, Rowe y Dawson, 1964) con la alfarería Chanapata encontramos que la ubicación cronológica de las tres piezas en referencia está entre los 700 a 600 años a. C., correspondiente a la Fase 8 de Paracas u Ocucaje; ya que esta fase registra felinos con el rostro de frente y el cuerpo de perfil (Calero, 2018, p. 31) similares al personaje principal representado en la pluma Echenique (figura 05).

\section{LA ARQUITECTURA RELIGIOSA EN LA ICONOGRAFÍA}

La pluma Echenique mide $20 \mathrm{~cm}$ de largo y fue faccionada en oro (figura $02 \mathrm{~b}$ y $04 b$ ), según nuestro análisis morfofuncional, la pluma fue usada como tocado (figura 06), esta constituye una pieza fundamental para entender la iconografía presente tanto en el escudo de Cuzco o disco Echenique como en el disco Oberti, ya que contiene elementos claves para comprender sus representaciones. 


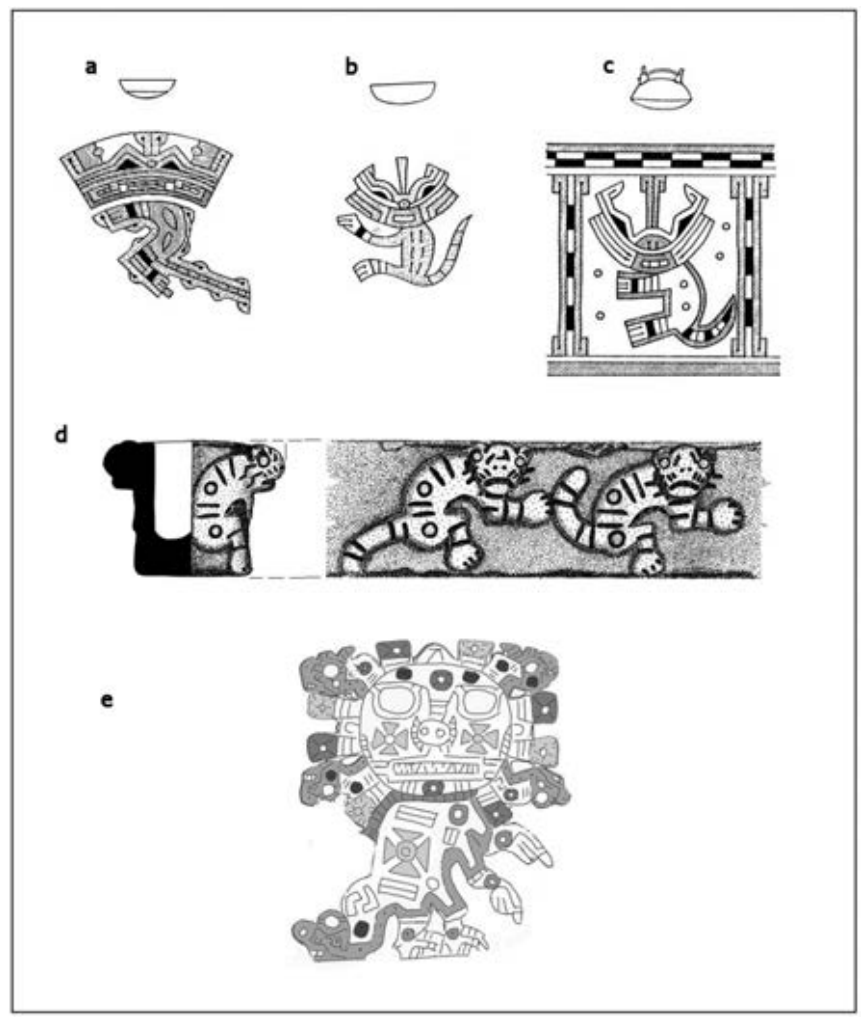

Figura 05. Comparaciones estilísticas con la columna de Ica. $a, b, c)$ Iconografía correspondiente a la Fase Paracas 8; nótese el felino con el rostro de frente y el cuerpo de perfil, en posición sedente con el tórax y cabeza inclinados hacia adelante. $d$ ) Alfarería estilo Bandojan, contemporánea a la pluma Echenique procedente de la pampa de Anta-Cuzco. e) Pluma Echenique con representación felínica y con similares atributos a las figuras $a, b, c$.

La iconografía de la pluma está dividida en tres partes: la superior, ocupada por el personaje principal; la media inferior muestra la representación de un círculo con dos cabezas zoomorfas a cada lado y dos personajes o celebrantes en los extremos y la última porción está ocupada por el personaje inferior central (ver figura 07).

El personaje principal de la pluma porta en el lado derecho un recipiente, que podemos decir que es de madera pues está sostenido por tallos y, además, al cortar transversalmente las lianas, estas presentan cruces o figuras semejantes; este indicio funciona de igual forma para el personaje inferior izquierdo que también porta un recipiente a la altura de la espalda.

Ambos recipientes están diseñados con una perspectiva muy particular que resalta la base de los mismos (figura 08a y 08b), pues, en una perspectiva real, los íconos de la base de estos recipientes no se distinguirían mucho (figura 08c). La iconografía de la pluma fue ejecutada de modo que al girar las representaciones de los recipientes a $180^{\circ}$, permita percatarnos de un diseño que representa una estructura elevada.

Llegando a este punto, se presta atención a la parte media inferior de la pluma, en la que se distingue un círculo con cuatro camélidos en su interior y dos cabezas zoomorfas a ambos lados, cuya perspectiva de representación es similar a la de los 


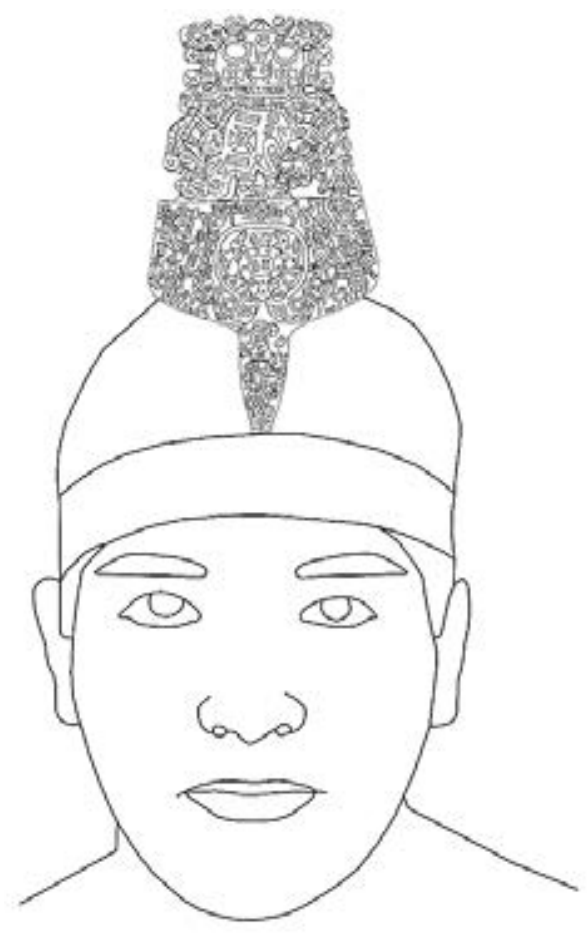

a

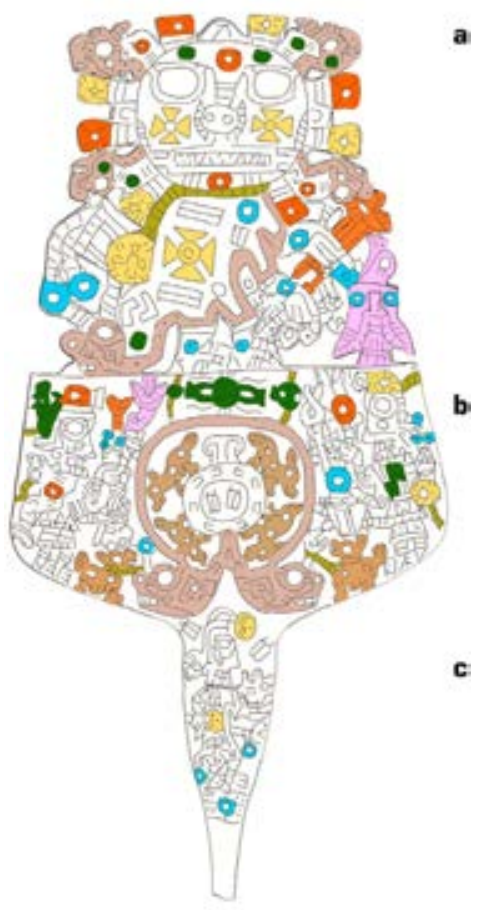

Figura 06. Posible uso de la pluma Echenique.

Figura 07. Pluma Echenique. a) Porción superior ocupada por la Diosa con apéndices. b) Porción media; nótese el icono circular rematado en dos cabezas zooformas, flanqueado a sus costados por dos personajes antropomorfos. c) Porción inferior, que soporta un personaje antropomorfo portando un báculo. 


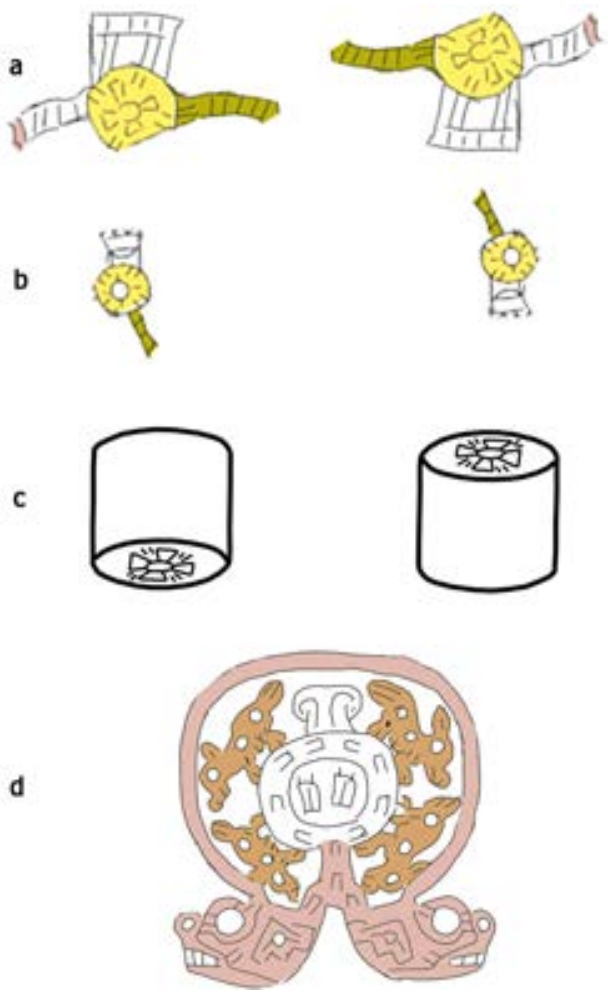

Figura 08. $a, b)$ Recipientes cilíndricos portados por el personaje principal de la pluma Echenique $y$ el personaje inferior izquierdo. Nótese la perspectiva exagerada de las bases que al ser invertidas, nos dan la idea de estructuras arquitectónicas encima de una colina. c) Dibujo realista de un recipiente cilíndrico. d) Representación de arquitectura tomada de la porción media de la pluma Echenique; nótese la rampa central y los dos ofrendatorios a los costados.

recipientes antes descritos girados a $180^{\circ}$. Nuestro análisis nos lleva a proponer, que se trata de una representación arquitectónica edificada en la cima de un cerro, en la que se halla una planta circular con una pequeña rampa, un altar en medio y dos ofrendatorios representados por las cabezas zoomorfas ubicadas a ambos lados de esta arquitectura circular (figura 08d).

Los atributos citados, nos invitan a revisar las investigaciones referentes al Horizonte Temprano e Intermedio Temprano, especialmente las que han estudiado edificaciones arquitectónicas religiosas que tengan una datación de 700 a 600 años a. C., en la región de Cuzco.

Así, Rowe notició su descubrimiento en el yacimiento arqueológico de Chanapata como sigue: "hemos podido reconocer partes de un patio semisubterráneo y de una plataforma elevada entre las construcciones antiguas" (1943, p. 42). Esta sería la única referencia que el autor realiza respecto a este templo; ya que el libro que publicó sobre sus investigaciones en el Cuzco, donde detalla sus excavaciones y descubrimiento en el sitio de Chanapata, no incluye más información de este aspecto (Rowe, 1944).

Transcurridos más de cincuenta años desde el develamiento de Chanapata, el arqueólogo Julinho Zapata realizó importantes aportes al conocimiento de las so- 
ciedades tempranas de la región de Cuzco, como la arquitectura hallada en Waro, ubicado en la cuenca media del río Vilcanota:

En el mismo frente de excavación, se registraron también vestigios de una sucesión de hasta tres niveles de terrazas, y específicamente en la UE 8000, fue encontrada una escalinata de acceso construida con piedras, que permite el tránsito desde la primera plataforma hasta el patio hundido cuadrangular con los ángulos curvos. En tanto, en el segundo frente de excavación, se encontraron dos muros de contención, que al parecer enmarcaban una plaza hundida (Zapata, 1998, p. 317).

Asimismo, este autor describe también el templo que registró en Muyu Urqo, próximo a la ciudad del Cuzco:

El hallazgo más relevante en cuanto a arquitectura ceremonial del Periodo Formativo del Cuzco fue encontrado enterrado en la cima del cerro Muyu Urqo. Se trata de un templo hundido rectangular de 16,80 metros de largo por 12,60 metros de ancho, ubicado en la parte central de la plataforma superior a 1,20 metros bajo el piso de la plaza (Zapata, 1998, p. 322).

Las dos arquitecturas religiosas excavadas por Zapata se ubicarían entre los años 600 a. C. a 200 d. C., tiempo que comprende la presencia de los estilos Chanapata, Paqallamoco o Chanapata Derivado y el estilo Bandojan. A esto se suman los datos obtenidos en las excavaciones a orillas de la laguna de Huaypo en Chinchero (Cuzco), realizadas por Davis y Delgado, quienes concluyen que durante el 400 al 100 a. C., hubo varios cambios en el sector ceremonial del pueblo de Yuthu. Este pueblo se habría organizado para construir una plataforma y una estructura soterrada donde realizaban actividades ceremoniales (Davis y Delgado, 2008, p. 97; 2009, p. 370; Davis, 2010, p. 402-403).

En las descripciones de la arquitectura descubierta por Rowe (1943) en Chanapata, las registradas por Zapata (1998) en Waro y Muyo Orqo y la excavada por Davis y Delgado $(2008 ; 2009 ; 2010)$ en Yuthu no detallan, si el acceso a dichos templos está ubicado al centro o al costado de las estructuras en referencia, pese a que Zapata sí describe una rampa y escalinata de acceso al templo de Waro.

Para el propósito del presente estudio, debemos resaltar que estos emplazamientos arquitectónicos se ubican encima de colinas o pequeños cerros, atributo coincidente con nuestra identificación iconográfica del templo de la pluma Echenique; forma de arquitectura que no puede corresponder a la región del altiplano o a la tradición religiosa Yaya-Mama, identificada por Sergio Chávez, ya que "las construcciones de templos de Yaya-mama consisten en patios rectangulares, semisubterráneos y sin techo, con una entrada ubicada fuera del centro, en una de las paredes" (Chávez F., 2018, p. 26). No obstante, como recalcamos líneas arriba, en la represen- 


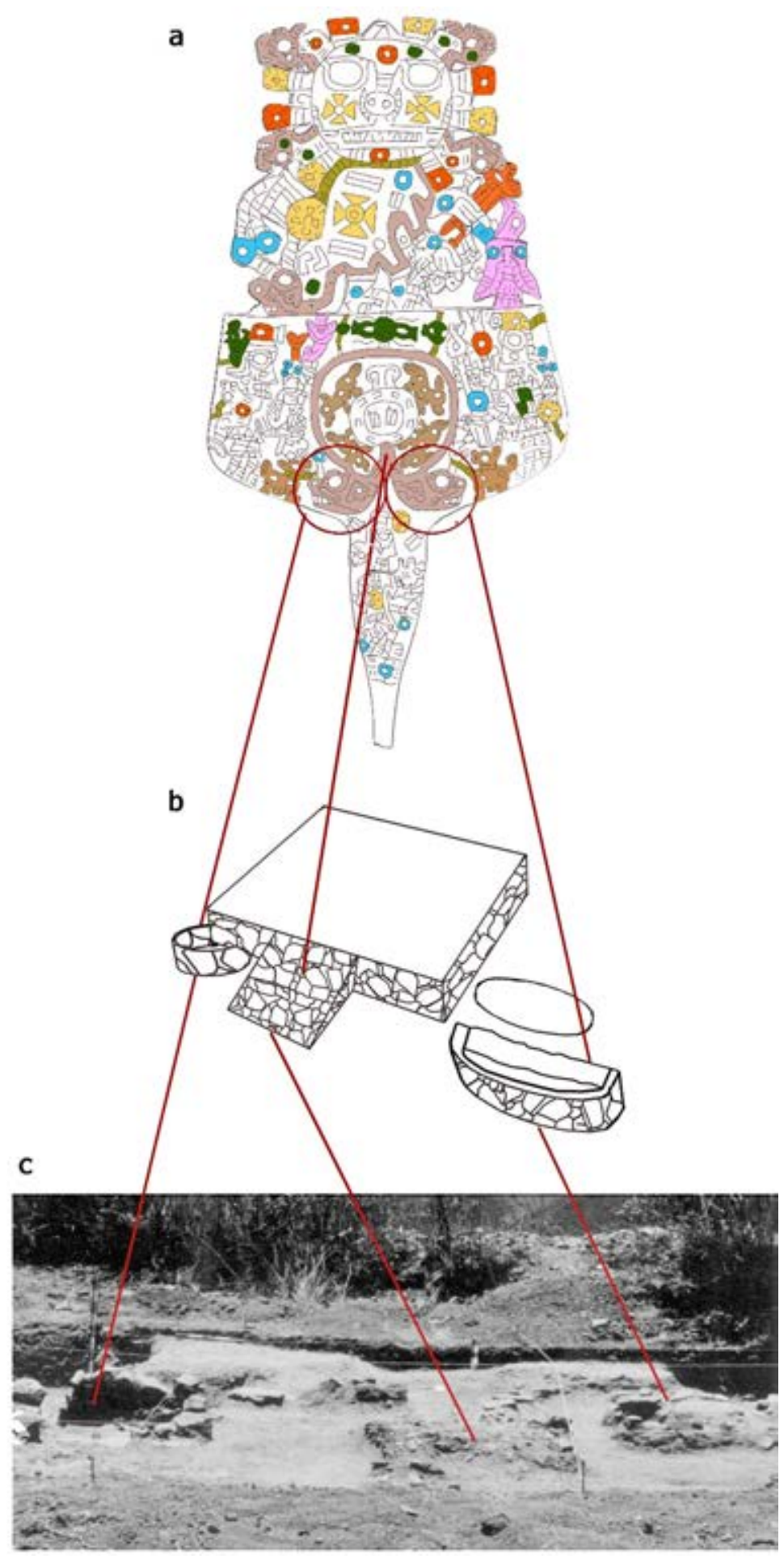

Figura 09. a) Representación de estructura arquitectónica presente en la pluma Echenique, consistente en un altar, una rampa $y$ dos ofrendatorios. $b, c)$ Reconstrucción y fotografía del Templo con una datación de 600 a 250 años a. C., hallado en Chumo-Sicuani por Jorge Calero F. y Mildred Fernández P. (2015), el que evidencia el mismo concepto de templo que la pluma Echenique (Figura $N^{\circ} 9 a$ ), con dos ofrendatorios y una plataforma con su acceso en rampa. 
tación de la arquitectura pública de la pluma, el vano de acceso se ubica al medio y no a un costado como es característico en los templos Yaya-Mama (Chávez, 2004).

Una evidencia de la presencia de arquitectura pública con los atributos identificados en la iconografía de la pluma Echenique, la encontramos edificada en medio de un montículo o cerro de la comunidad campesina de Chumo, distrito de Sicuani, provincia de Canchis; que corresponde al 600 a. C., hasta el 250 a. C. (Calero y Fernández, 2015, p. 482, 485; 2019, p. 08, 16,17, 19), en cuya cima se encontró una plataforma cuadrangular, con una rampa al medio y dos ofrendatorios a los lados de esta (figura 09b y 09c).

La similitud con la iconografía de la arquitectura religiosa que presenta la pluma Echenique (figura 09a) es extraordinaria, además que, su datación junto a los discos Oberti y Echenique sustentada en las comparaciones con la iconografía de la columna de Ica, determinan que las tres piezas de la colección corresponden a los años 700 a 600 a. C.

Llegado a este punto, es necesario realizar una exploración iconográfica que nos permita establecer hasta que período se continuaron usando las representaciones iconográficas de templos evocados a la Diosa con apéndices, así como detallar sus cambios representacionales en el tiempo.

Para dicho propósito, consideramos pertinente presentar una revisión más detallada de la evolución iconográfica de esta forma de arquitectura.

En primer lugar, cabe resaltar la recurrente ubicación de la Diosa con apéndices, posicionada siempre en la parte superior de la arquitectura pública, ya sea la representación completa de la Diosa como se observa en la pluma Echenique; o resumida, como la que encontramos en los discos Echenique y Oberti.

Es cierto que la Diosa con apéndices ha sufrido algunas modificaciones en el tiempo; sin embargo, estas no fueron muy significativas, pues sus representaciones posteriores o tardías conservan los atributos generales presentes en la pluma Echenique y los discos Echenique y Oberti; origen de dicha tradición iconográfica y religiosa.

Iniciamos la revisión requerida, señalando que algunas representaciones iconográficas similares fueron advertidas por Young (2004, p. 94) como, en el caso de un tejido del 200 al 400 años d. C., donde encontramos a la Diosa de la pluma Echenique representada de manera resumida. En la parte inferior de la misma, se tiene un ícono escalonado que contiene un rectángulo sin esquinas, de donde salen cuatro líneas o caminos; los dos horizontales empatan a dos cabezas zoomorfas, de modo que, tenemos la representación de una pirámide escalonada con su rampa y dos ofrendatorios a sus costados (figura 10). 
Por otro lado, en una tableta de rapé decorada - con una datación relativa de 200 a 1000 años d. C. - procedente de San Pedro de Atacama en Chile (figura 11), destaca la representación de este personaje llevando en el pecho una cruz similar a la que porta la Diosa presente en la pluma Echenique. Dicho personaje está ubicado en la parte superior de una pirámide escalonada con un templo en forma de " $\mathrm{H}$ " en el centro y dos ofrendatorios a los lados.

En la Portada del Sol de manufactura Tiahuanaco (400 a. C. a 1000 d. C.), encontramos que la Diosa con apéndices, al igual que, la de la pluma se ubica sobre un templo de estructura similar a los anteriores descritos, mostrando en el pecho la representación de un templo con las características arriba señaladas (figura 12).

En una tableta de rapé procedente de San Pedro de Atacama, datada entre los años 400 a 1000 d. C., se distingue la representación de la misma Diosa con atributos zoomorfos; posicionada en encima de una pirámide que contiene un templo con sus dos ofrendatorios a los lados (figura 13).

Asimismo, en un vaso Tiahuanaco (600 a 1100 d. C.) procedente de Moquegua (Perú), la Diosa muestra un ícono en forma de "I" a la altura de la garganta, el mismo que está representando los templos en forma de " $\mathrm{H}$ " que venimos describiendo; cuya modificación se debe al escaso espacio para representarlo en su forma original (figura 14). Un caso similar encontramos en una vasija Wari, que muestra a la diosa portando dos báculos y en su pecho se observa el icono en "I"; que representa, igualmente, la forma invertida del templo en " $\mathrm{H}$ " (figura 15).

En la alfarería de estilo Lucre de la región de Cuzco (1100 a 1450 d. C.), encontramos también los iconos en forma de "I", flanqueados esta vez por representaciones de camélidos: evidenciando una continuidad iconográfica de templos (figura 16). Estos elementos reiterativos en el tiempo, se complementan con los dibujos de Gua-

\footnotetext{
Figura 10. Tejido estilo Pucara provincial, correspondiente a los años 200 a $400 \mathrm{~d}$. C., donde identificamos a la Diosa con apéndices representada de manera resumida, al igual que en los discos Echenique y Oberti, la que en su parte inferior tiene la representación de una pirámide escalonada con una rampa $y$ dos ofrendatorios a los costados.
}

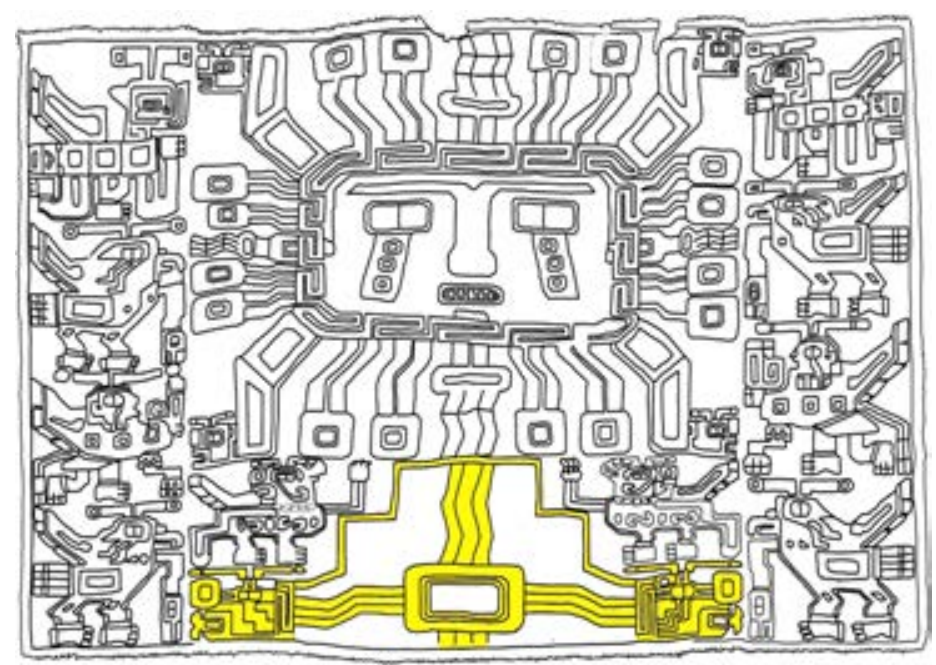




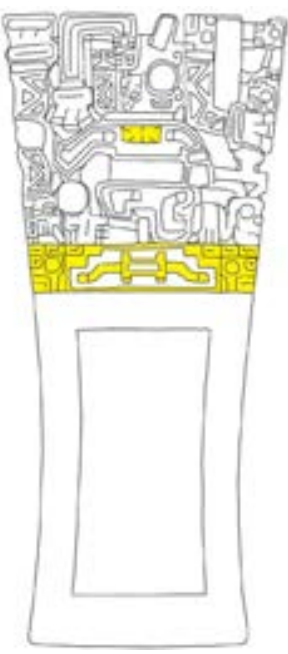

Figura 11. Tableta de rapé hallada en San Pedro de Atacama (Chile), con una datación de 400 a 800 años $d$. C. Nótese que su personaje principal está dispuesto encima de un templo en " $H$ " $y$ que este lleva una cruz en el pecho al igual que el personaje principal de la Pluma Echenique.

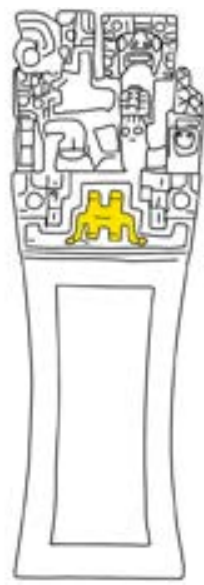

Figura 13. Tableta de rapé (400 a 1000 años d. C.), nótese a la Diosa con atributos zoomorfos y ubicada encima de un templo en " $H$ ", flanqueado por dos ofrendatorios.

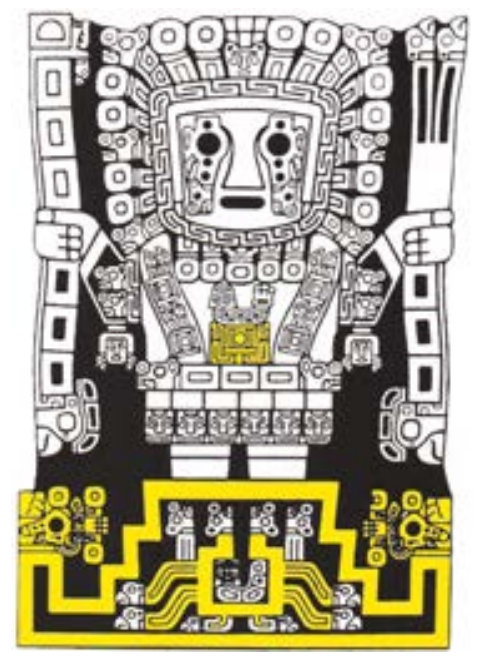

Figura 12. Representación iconográfica extraída de la Portada del Sol correspondiente al estilo Tiahuanaco, con una datación relativa de 400 a. C. a 800 años d. C., ubicada en Tiahuanaco-Bolivia. Esta iconografía representa a la Diosa parada sobre un templo, portando en su pecho también el icono representativo de un templo.

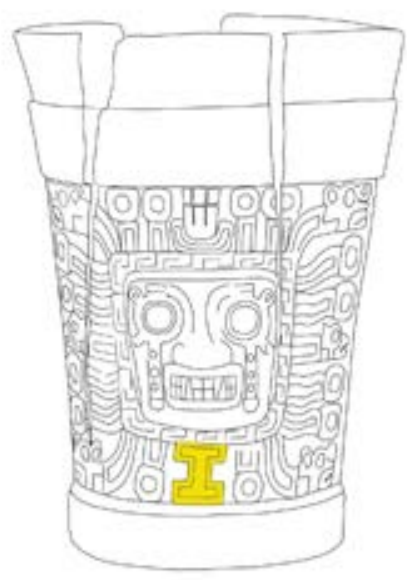

Figura 14. Vaso de madera procedente de Moquegua-Perú, de estilo Tiahuanaco. Nótese la representación de la Diosa de manera resumida que lleva como gargantilla la representación de un templo en " $H$ ", el que fue invertido y colocado en forma de "I". 


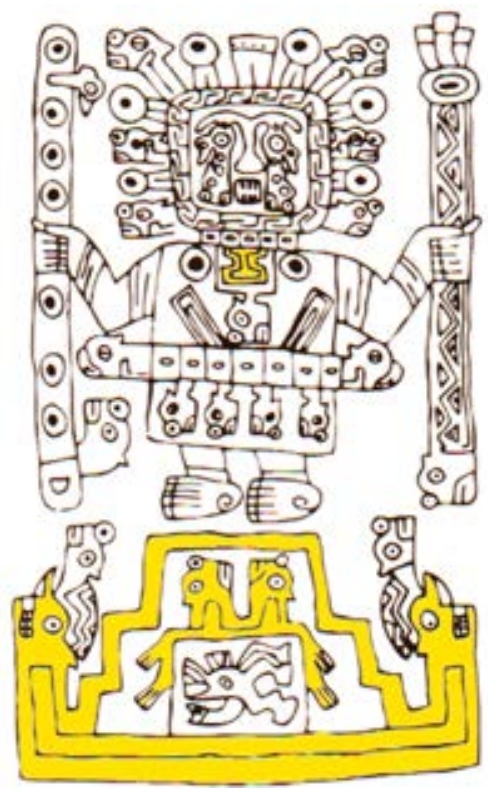

Figura 15. Representación estilo Wari de la Diosa $(900$ a $1100 \mathrm{~d}$. C.). Nótese que está dispuesta encima de un templo y, asimismo, lleva el icono del templo en forma de "I" como pectoral.

mán Poma de Ayala, referentes a la población del Qollasuyo de la época inca; en los que, los personajes con bonete tanto cilíndrico como esférico portan un ícono en forma de "I" a manera de gargantilla.

Asimismo, en otros dibujos de Guamán Poma en los que representa personajes Qollas del tiempo del Virreynato, estos también portan gargantillas en forma de "I"; pese a que ya lucen atuendos o prendas europeas y andinas (ver figuras 17a, 17b, $17 \mathrm{c}$ y $17 \mathrm{~d})$.

Finalmente, cerca de Atacama en Chile se tiene un petroglifo que está representando a la Diosa portando dos báculos; la que está en medio de dos camélidos unidos por sus partes posteriores (figura 18d). Esta representación develaría el porqué de los templos en "H" (figura 18b) y en "I" (figura 18c), que tienen su origen en la iconografía de la pluma Echenique (figura 18a), cuya representación incluye camélidos dentro del templo.

Es interesante identificar que los ritos expresados en los templos, cuyas imágenes describimos anteriormente incluyen; camélidos, plantas maestras, y tabletas de rapé como parafernalia del culto a la Diosa de la cabeza con apéndices; la que posteriormente se constituirá en la Diosa que lleva los dos báculos.

Hasta este punto, se establece que la representación iconográfica de arquitectura empleada para rituales de fertilidad de camélidos con el uso de plantas enteógenas, se inicia hacia el 700 a. C., con la representación que acabamos de describir presente en la pluma Echenique. 


\section{DISCUSIÓN}

La evidencia nos demuestra, que la representación iconográfica de arquitectura pública relacionada al culto de la Diosa con apéndices, se ha mantenido desde el 700 a. C., hasta aproximadamente el $1100 \mathrm{~d}$. C., tiempo en que se deja de representar a la Diosa, pero se continúa usando el icono de la "I" asociado a camélidos, como en el caso de la alfarería Lucre y Killke del valle del Cuzco.

Debemos resaltar además, que la representación de templos en el pecho o próximos a este, se inicia con la pluma Echenique al contener esta el icono de la cruz, cuya presencia habíamos indicado en un trabajo anterior; denota la condición femenina de dicho personaje (Calero, 2018, p. 100). Otros indicios los encontramos en el personaje Tiahuanaco de la figura 19b, datado en 200 a 1000 d. C., que ostenta en el pecho una cruz o la representación de arquitectura religiosa; asimismo, el personaje de la Portada del Sol, en la figura 19c, lleva en el pecho el ícono representativo del templo, así como la figura 19e -correspondiente al estilo Wari Pacheco-, lleva también el icono del templo en el pecho; por último, con esta misma característica se tiene los dibujos de personajes Qollas realizados por Guamán Poma de Ayala en 1615, entre ellas: la figura 19f, correspondiente a un capitán de la época inca y la figura $\mathrm{N}^{\circ} 19 \mathrm{~g}$ que muestra a un noble colla de la época virreinal (Guamán Poma de Ayala, 1615/1993: 129, 613).

\section{CONCLUSIONES}

Es evidente la evolución iconográfica de los templos circulares del Horizonte Temprano como el representado en la pluma Echenique, los que posteriormente se tor-
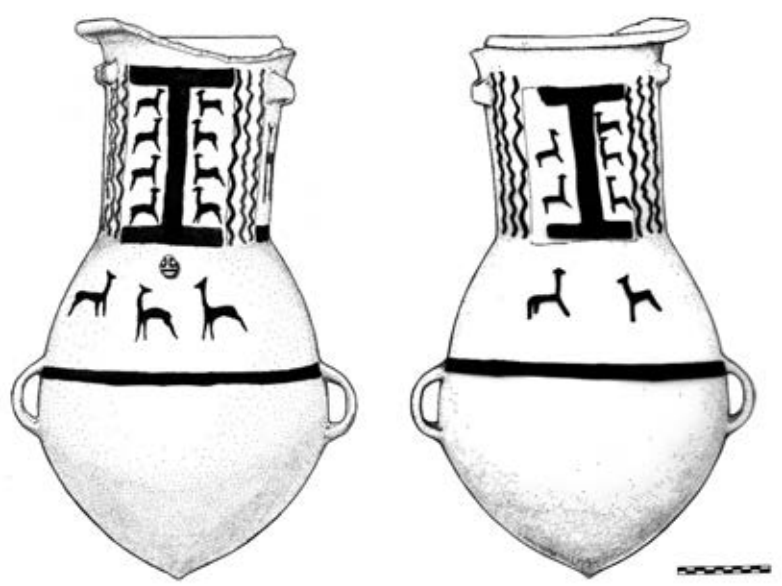

Figura 16. Vasija estilo Lucre, conservada en el Museo Inca de la Universidad Nacional de San Antonio Abad del Cusco. 

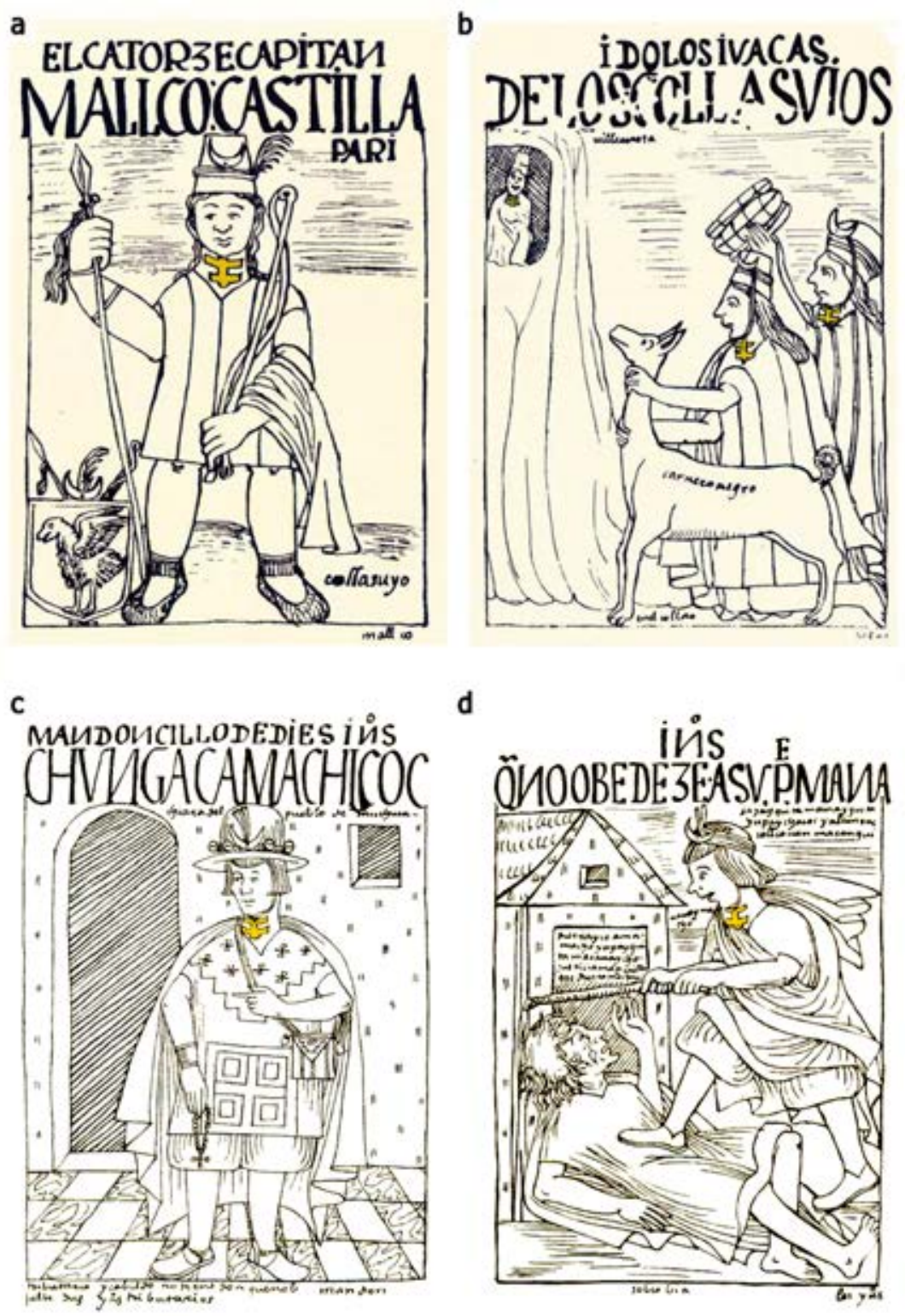

Figura 17. Dibujos de Felipe Guamán Poma de Ayala 1615 [1993] publicados en su obra. "Nueva Crónica y Buen Gobierno", donde muestra personajes collas portando gargantillas en forma de " $I$ ", símbolo representativo del templo.

a) El catorce capitán, Mallco Castilla Pari. Collasuyo; muestra un colla de la época inca.

b) Ídolos y Uacas de los Collasuyos, grafica personajes collas de la época inca.

c) Mandoncillo de diez indios. Chunga camachicoc, chiara del pueblo Muchuca. Ilustración de un colla de la época virreinal

d) Indios que no obedecen a su padre. Ilustra un colla de la época virreinal 

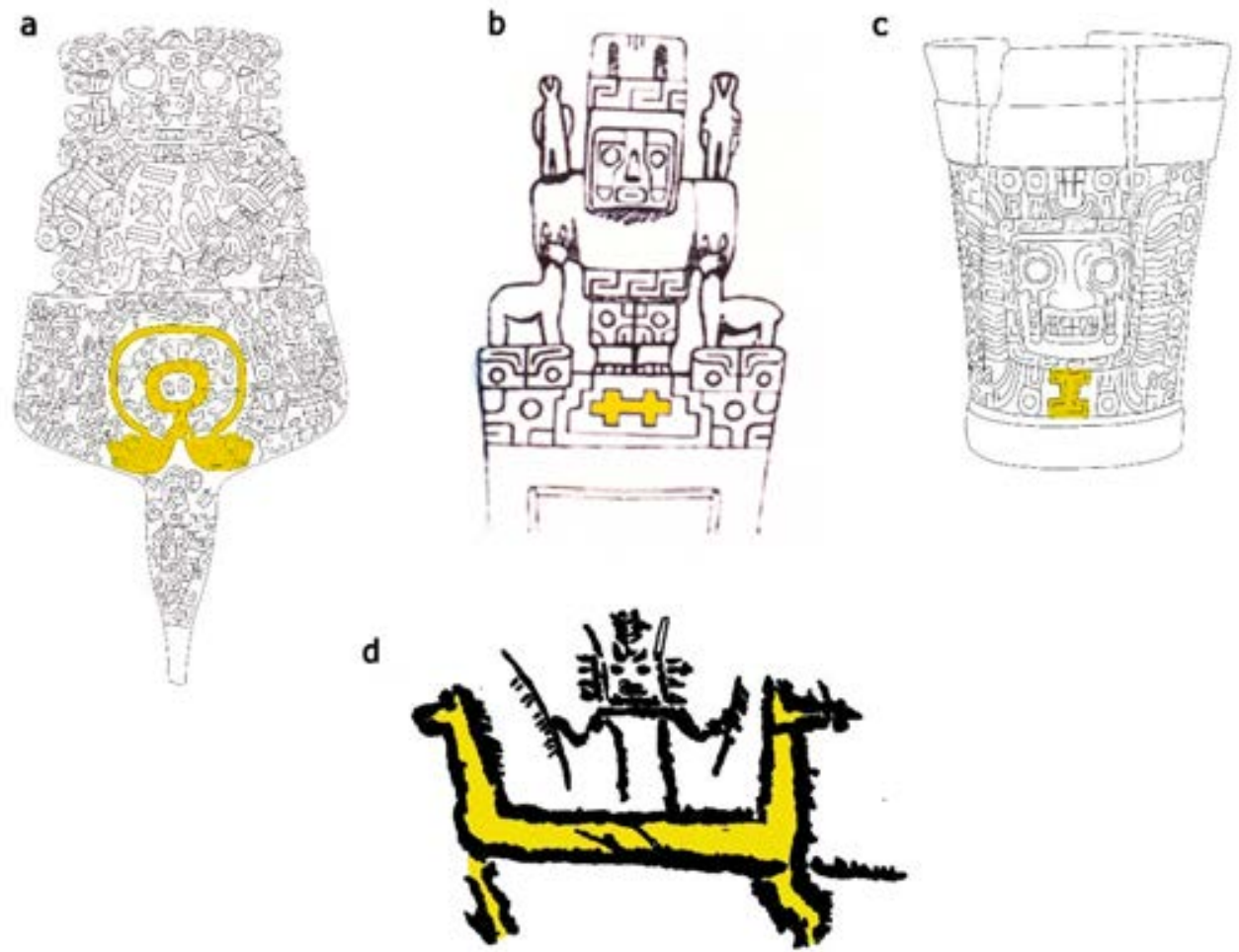

Figura 18. En Atacama se tiene un petroglifo que representa a la Diosa portando dos báculos y está en medio de dos camélidos unidos por sus partes posteriores (figura 18d), representación que devela el motivo del por qué de los templos en "H" (figura 18b) y en " $I$ " (figura 18c), que tienen su origen en la iconografía de la pluma Echenique (figura 18a).

naron templos en forma de " $\mathrm{H}$ "; arquitectura ideológicamente conformada por dos camélidos unidos por sus grupas, tal y como se aprecia en el petroglifo de la Diosa con apéndices; para finalmente pasar a las representaciones de esta arquitectura en forma de "I", la que subsistió hasta el siglo XVII en tiempos del Virreynato (ver figura 19).

La representación de los templos desde el Horizonte Temprano hasta el Virreynato están relacionadas al ganado y al culto de la Diosa de los apéndices; aunque ciertamente, dichas representaciones iconográficas han variado en forma, pero su contenido ideológico se mantiene; es así que en el Horizonte Temprano, el templo de la pluma Echenique está asociado a los camélidos, al igual que los plasmados en las vasijas Lucre y Killke del Valle del Cuzco, correspondientes al Período Intermedio Tardío. 


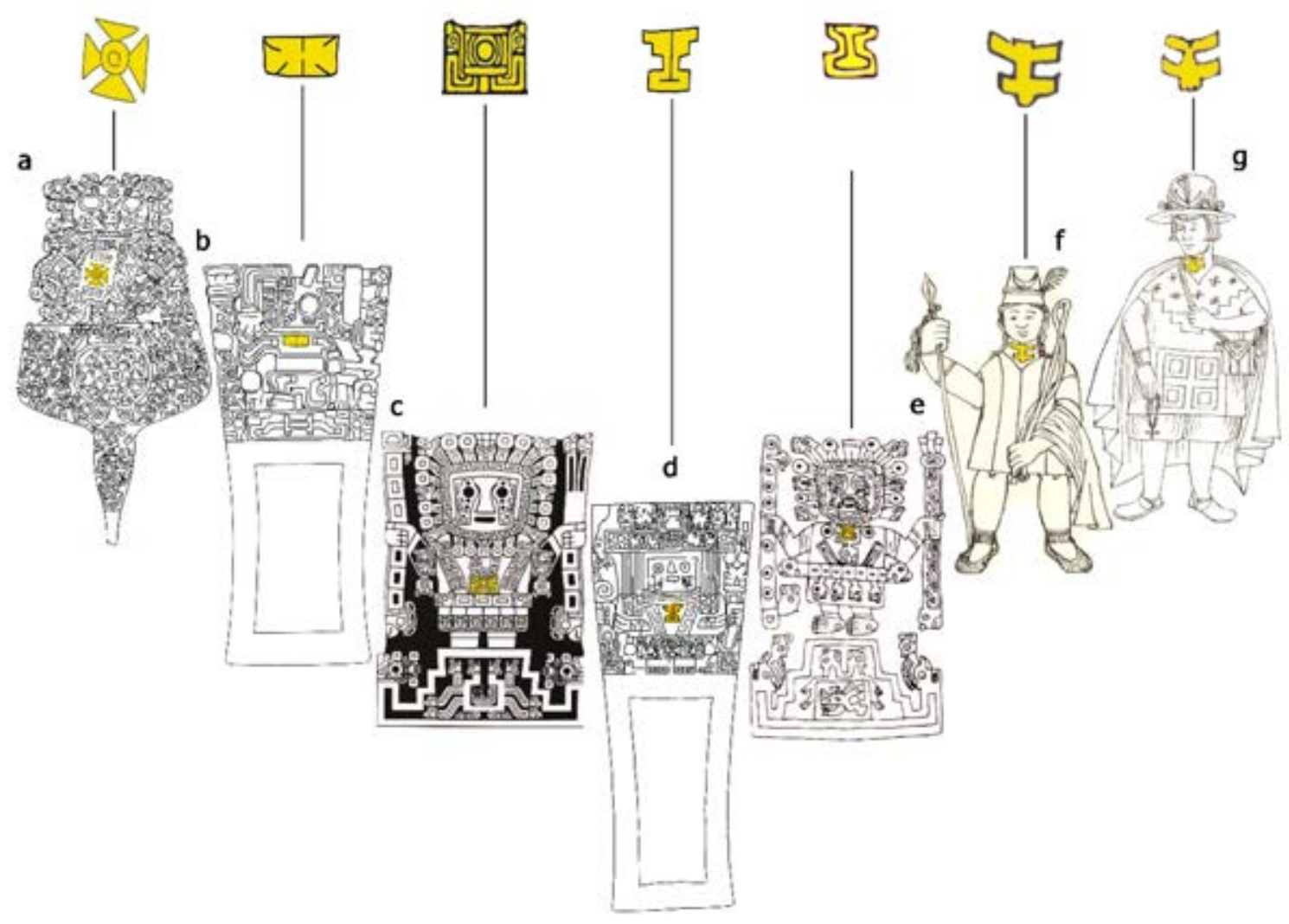

Figura 19.

a) Pluma Echenique (700 a 600 años a. C).

b) Tableta de rapé procedente de Atacama Chile (200 a 100 años d. C).

c) Personaje principal de la portada del Sol, Tiahuanaco-Bolivia (400 a 800 años d. C.).

d) Tableta de rapé. San Pedro de Atacama, Chile (400 a 1000 años d. C.). Dibujado de la foto de Young-Sánchez (2004, p. 21).

e) Wari estilo Qonchopata (aproximadamente 600 años d. C.).

f) El catorce capitán, Mallco Castilla Pari. Collasuyo, muestra un colla de la época inca(1450 a 1532 años d. C).

g) Dibujo de Guamán Poma de Ayala, titulado. "Mandoncillo de diez indios. Chunga camachicoc, chiara del pueblo Muchuca”. Ilustración de un colla de la época virreynal (1615 años d. C). 


\section{REFERENCIAS BIBLIOGRÁFICAS}

Calero Flores, J. A. (2018). El escudo de Cusco: El secreto de los Andes. Primera edición. Municipalidad del Cusco. Cusco: Imprenta Eco Print E.I.R.L.

Calero Flores, J. A. (2017). El Escudo de Cusco o Disco Echenique. INKARI Suplemento Cultural. Diario El Sol del Cusco. Año I. Edición I. 17 de febrero. 4-5.

Calero Flores, J. A. (2000). Dios de Chanapata. Revista Vía Láctea. Agosto. 16

Calero Flores, J. A. (1997). El Disco Echenique o Escudo del Cusco. Qollana. Instituto de Investigaciones Antropológicas Qollana. $\mathrm{N}^{\circ}$ 05. Año 05, octubre-noviembre. 30-33.

Calero Flores. J. A. y Fernández Palomino, Mildred. (2019). Sicuani y el Sur Andino: Las primeras sociedades con alfarería. Cuzco. Centro de Estudios Regionales Andinos Bartolomé de Las Casas. (CBC). ARCHAEOCUZCO.

Calero Flores, Jorge A. (2015). Arqueología de los Períodos Alfareros Tempranos del Distrito de Sicuani-Cusco. Tesis de Licenciatura. Carrera Profesional de Arqueología, Facultad de Ciencias Sociales. Cuzco: Universidad Nacional de San Antonio Abad del Cusco.

Chávez Farfán, Sergio J. (2018). Identification, Definition, and Continuities of the Yaya-Mama Religious Tradition in the Titicaca Basin. En William H. Isbell, Mauricio I. Uribe, Anne Tiballi, Edward P. Zegarra (Ed.). Images in Action. The Southern Andean Iconographic Series (pp. 17-49). USA: The Cotsen Institute of Archaeology at UCLA.

Chávez Farfán, S. J. (2004). The Yaya-Mama Religious Tradition as an Antecedent of Tiwanaku. En Levinson, L. and Melun, A. (Ed.), Tiwanaku Ancestors of the Inca (pp. 70-75). Published by Denver Art Museum and University of Nebraska Press. Lincoln and London.

Davis, Allison R. (2010). Excavations at Yuthu. A community study of an early village in Cusco, Perú (400-100 BC). A dissertation submitted in partial fulfillment of the requirements for the degree of Doctor o Philosophy (Anthropolgy). USA: University of Michigan.

Davis, Allison R. y Delgado González, C. M. (2008). Yuthu sitio Formativo a orillas de la laguna de Huaypo Cusco. Revista Saqsaywamán, 8, pp. 85-105. Instituto Nacional de Cultura. Dirección Regional de Cultura Cusco. Subdirección de Investigación.

Davis, Allison R. y Delgado González, C. M. (2009). Investigaciones arqueológicas en Yuthu: nuevos datos sobre el Periodo Formativo en el Cusco, Perú (400-100 a. C.). Boletín de Arqueología PUCP, 13, pp. 347-372. 
Fernández Palomino, M. (2017). Los Templos Cusqueños (600 a 250 años a. de C.). INKARI Suplemento Cultural. Diario El Sol del Cusco. Año I. Edición I. 17 de febrero, 1-3.

Guamán Poma de Ayala, F. (1993). Nueva Coronica y Buen Gobierno. 1er edición. Lima: Fondo de Cultura Económica. (Original publicado en 1615).

Markham, Clements R. (1920). Los Incas del Perú. Versión castellana de Manuel Beltroy. Prólogo del Dr. Julio C. Tello. Lima: "s.n."

Markham, Clements R. (1856). Cuzco: A journey to the ancient capital of Peru; with an account of the history, language, literature, and antiquities of the Incas. And Lima: A visit to the capital and provinces of modern Peru; with a sketch of the viceregal government, history of the republic, and a review of the literature and society of Peru. Chapman and Hall, London.

Menzel, D., Rowe, J. H. y Lawrence E. D. (1964). The Paracas Pottery of Ica a Study in Style and Time. University of California Publications in American Archaeology and Ethnology. Editors (Berkeley): R. F. Heizer, E. A. Hammel, R. F. Murphy. Vol. 50. U.S.A.

Rowe, J. H. (1943). Chanapata: la cultura pre-incaica del Cuzco. Revista Tupac Amaru, 2, pp. 41-43

Rowe, J. H. (1944). An Introduction to the Archaeology of Cuzco. Expeditions to Southern Peru. Peabody Museum of American Archaeology and Ethnology, Harvard University. Vol. XXVII. N ${ }^{\circ}$ 2. Report $\mathrm{N}^{\circ}$ 2. Cambridge, Massachusetts. U.S.A. Published by the Museum.

Rowe, J. H. (1960). Tiempo, estilo y proceso cultural en la Arqueología Peruana. $2^{\text {da }}$. Edición corregida. Instituto de estudios Andinos. Berkeley. California.

Rowe, J. H. (1976). El arte religioso del Cuzco en el Horizonte Temprano. Ñawpa Pacha, 14, pp. 1-30. Berkeley.

Rowe, J. H. y Menzel, D. (1967). Peruvian Archaeology, selected readings. Department of Anthropology. University of California. Berkeley. Peek publications.

Tello, J. C. (1923). Wira kocha Inca, 1(3), 93-320, 1(3) 583 - 606. Lima.

Tello, J. C. (1938). Una notable insignia de oro del antiguo Perú. Revista peruana de viajes, artes, letras y actualidad. Año XII. Nº 137.

Young-Sánchez, M. (2004). Tiwanaku: Ancestors of the Inca. Tiwanaku Ancestors of the Inca. Denver Art Museum. University of Nebraska Press. Lincoln and London.

Zapata Rodríguez, J. (1998). Los cerros sagrados: Panorama del periodo Formativo en la cuenca del Vilcanota, Cuzco. Boletín de Arqueología de la Pontificia Universidad Católica del Perú, 2. Departamento de Humanidades, especialidad de Arqueología. 


\section{SOBRE EL AUTOR}

\section{Jorge A. Calero Flores}

Licenciado en Arqueología por la Universidad Nacional de San Antonio Abad del Cusco. Máster en Valoración, Gestión y Protección del Patrimonio Cultural por la Universidad de Vigo (España). Director Académico del Centro de Investigaciones Archaeocuzco. Docente en la Escuela Profesional de Arqueología de la Universidad Nacional de San Antonio Abad del Cusco. Tiene como ejes de investigación; la arqueología, etnografía y etnohistoria. Recientemente ha publicado:

El escudo de Cusco: El secreto de los andes, libro auspiciado y publicado por el Gobierno Municipalidad del Cusco. 2018; Sicuani y el sur andino. Las primeras sociedades con alfarería, libro auspiciado y publicado por el Centro Bartolomé de las Casas y Archaeocuzco. 2019; La casa del patrón: Documentos para la historia del templo de San Sebastián-Cusco. 2020, Qhenchapata 1: Ayllu Sucso Auccaylle, Arqueología de Alto Qosqo, Distrito de San Sebastián - Cusco, ambos libros editados por la Municipalidad del Distrito de San Sebastián - Cusco. 2021. 